\title{
Nodal Non-Hodgkin's Lymphoma: Histomorphological Study with Special Emphasis on Immunomarker Profile of Nodal NHL
}

\author{
Jaimini Nisarg*, Shubha Rakesh Gupta, Mansi Faujdar and Nisarg Prakash Patel \\ SantokbaDurlabhji Memorial Hospital, Jaipur, Rajasthan, India
}

\begin{abstract}
Background: Lymphoid malignancies (LM) are a heterogeneous group of disorders that are broadly divided into Hodgkin disease(HD) and Non-Hodgkin Lymphoma (NHL). Diagnosinglymphoid malignancies based on morphology in conjunction with immunohistochemistry (IHC) forms the basis of WHOclassification and this has prognostic implications. The distribution of the major subtypes of non-Hodgkin's lymphoma (NHL) differs across geographic regions.

Material \& Method: Over all 147 cases of NHL over a period of 16 months (between March 2014 and June 2015) were diagnosed in the Department of Histopathology, SantokbaDurlabhji Memorial Hospital cum Medical Research Institute, Jaipur. Of the total of cases of lympho-proliferative disorders, the diagnosis of NHL was done by light microscopy alone and was classifiedaccording to International Working Formulation initially.All the cases diagnosed provisionally as NHL were taken up for immunophenotyping with Immunohistochemical (IHC) studies. The individual NHL cases were classified according to the WHO/REAL classification according to the positive or relevant negativeimmonophenotypic expression and tabulated to ascertain the morphological spectrum of NHL in this part of the country. Out of 147 cases of provisionally diagnosed NHL, 144 cases confirmed as NHL by IHC study. Overall concordance between light microscopy and IHC was $97.96 \%$.

Results: B-cell lymphomas formed $88.89 \%$, T-cell lymphomas formed $8.33 \%$ and unclassified NHL formed $2.78 \%$ of nodal NHLs. Diffuse Large B-Cell Lymphoma (DLBCL) was the most common subtype (61.11\% of all NHLs). B-cell small lymphocytic lymphoma, Follicular lymphomas, Mantle-Cell Lymphoma (MCL), marginal zone B-cell lymphomas, Burkitt's lymphoma and B cell lymphoblastic lymphoma amounted to $11.11 \%, 5.56 \%, 4.16 \%, 2.78 \%, 1.39 \%$ and $1.39 \%$ respectively. Among the T-cell lymphomas, T-cell lymphoblastic lymphoma, anaplastic large-cell lymphomas of T/null-cell type, and Angioimmunoblastic T-cell lymphoma (AITL) accounted for 4.16\%, $2.78 \%$, and $1.39 \%$ of all NHL cases, respectively.
\end{abstract}

Keywords: Hodgkin Disease, Non-Hodgkin Lymphoma, Immunohistochemistry

\section{Introduction}

Lymphoma presents the most challenging field of medical investigation, one in which immunity and neoplasia interface and in which new concepts and techniques are constantly tested. For the practicing pathologist, the important task of correctly diagnosing and classifying lymphomas arises frequently and can be difficult. To establish the treatment and determine the prognosis, Hodgkin's lymphoma (HL) and Non Hodgkin's lymphoma (NHL) must be identified accurately and phenotyped. The clinical management of lymphomas depends on correct diagnosis and classification. ${ }^{l} \quad$ Lymphomas are classified into two main types, Hodgkin's Lymphoma (HL) and non-Hodgkin's Lymphoma (NHL). NHL is the most common form and account for $83.17 \%$ of lymphoid tumors and $\mathrm{HL}$ accounts for $16.83 \%$ of cases. NHL can be Nodal-NHL (lymph node) and extra-nodal NHL. ${ }^{2}$

Incidence of Nodal NHL is about three times of extra-nodal NHL. Extra-nodal presentation of NHL occurs in 15-25\% of adult patients in U.S., is higher in Europe and is up to $40-50 \%$ in Asia. ${ }^{3}$
The classification of Non-Hodgkin's lymphoma has been a work in progress and has undergone many revisions to arrive at the current World Health Organization (WHO) classification used today. The most popular and important being Rappaport classification ${ }^{4}$ introduced in 1956 (used primarily in North America), the Kiel classification ${ }^{5}$ (used primarily in Europe) and the Lukes and Collins classification $^{6}$ introduced in 1974 (used primarily in North America).In August of 1976 Rappaport modified his classification. ${ }^{7}$ Working Formulation was developed in 1970 so that oncologists could translate clinical data derived in different institutions using different classification schemes. ${ }^{8}$ A desire to eliminate the continued confusion ultimately led to a new approach to lymphoma classification proposed by the International Lymphoma Study Group that used all available information, including morphology, immunophenotype, genetic and clinical features, to define a list of distinctive entities that could be uniformly diagnosed by hematopathologists. The proposal was published in 1994 and was known as the Revised European-American Lymphoma (REAL) classification?. 
The diagnosis of NHL is entirely dependent on excision biopsy of lymph node from relevant sites and final diagnosis is achieved by a combined evaluation of excision biopsy by light microscopic study for morphology and followed by immunohistochemical evaluation. In some cases, flowcytometry and molecular studies are essential for detecting clonal lymphoproliferations and their lineage. ${ }^{10}$

No other field in histopathology is as challenging as diagnosis of NHL because of wide spectrum of differential diagnosis ranging from reactive condition to inflammatory lesions to poorly differentiated malignancies. Excellent quality histology set up is required for evaluation along with specialized investigation like immunohistochemistry for phenotype. A small percentage of cases further required expensive and highly specialized techniques like molecular analysis and flowcytometry. Because of the complexity of diagnosis and the relative infrequency of lymphoma in general pathology practice, diagnosis of NHL and separating it from different entities require highly experienced and expert histopathologists with knowledge for collaborating light microscopic and IHC findings.

The purpose was to study the morphologic spectrum of NHL, to evaluate the IHC profile of various NHL, and also attempt clinicopathological correlation regarding age, sex and lymph nodal group involvement in the cases of Nodal-NHL, diagnosed in the department, during the study period.

In the present scenario interpretation of morphological features together with immunohistochemistry has become the bedrock for diagnosis and therapy of lymphoid malignancies. These studies have not only provided the objective classification but have identified the antigens that can be targeted for therapy.

\section{Method \& Material}

A total of 147 consecutive cases of NHL diagnosed over a period of 16 months at Department of Histopathology, Santokba Durlabhji Memorial Hospital cum Medical Research Institute, Jaipur were studied prospectively. Tissue sections were obtained from paraffin blocks and stained with Hematoxylin and Eosin (H\&E). After recording diagnosis based on morphology, the relevant cases were subjected to immunohistochemical staining. Pretreatment employed microwave technique for antigen retrieval and detection was done using labeled strepavidin biotin peroxidase complex. An IHC lab with a panel of CD20, CD3, CD23, Cyclin D1, Bcl6, CD10, MIB1, LCA, CD99, Tdt, Pax-5, CD5, CD2, CD4, PD1, CD30, Alk protien, CD15, CK, Chromogranin, CD56, \& S100 antibodies could be able to accurately diagnose and subtype $95.83 \%$ cases of NHL. A few cases (4.17\%) could not reach a final diagnosis with the basic panel of antibodies in our laboratory. Patients were informed about the importance of the study and consent was taken in all the cases. The clinical information regarding age, sex and site of the biopsy were taken into account on routine haematoxyline and eosin stained sections. Of the total of cases of lymphoproliferative disorders, cases diagnosed provisionally as NHL on light microscopy, were taken up for Immunophenotyping with IHC studies. The individual NHL cases were classified according to the WHO/REAL classification according to the positive or relevant negative immonophenotypic expression and tabulated to ascertain the morphological spectrum of NHL in this part of the country.

\section{Results}

NHL could be classified using working formulation into low grade, Intermediate grade and High grade on basis of morphology, and each group was further sub typed on basis of cell size and maturity.

$35(23.81 \%)$ cases of NHL with "small and mature lymphoid cells" were diagnosed as low grade NHL on basis of morphology. 80 (54.42\%) cases of NHL with medium to large "centroblastic and centrocytic cells" were diagnosed as intermediate grade NHL on basis of morphology. 14 $(9.52 \%)$ cases of NHL with medium to large "Blastoid cells" were diagnosed as High grade NHL (lymphoblastic lymphoma) in $8.84 \%$ cases and Burkitt's lymphoma in $0.68 \%$ case on basis of morphology. $18(12.25 \%)$ cases of NHL with large "immunoblastic cells" were diagnosed as high grade NHL on basis of morphology. (Table no. 1)

Out of 147 cases of provisionally diagnosed NHL, 144 cases confirmed as NHL by IHC study. 3 cases were diagnosed as "Other than NHL" (carcinoma and Hodgkin's lymphoma) after IHC study of provisionally diagnosed NHL on morphology. Overall concordance between light microscopy and IHC was being $97.96 \%$. (Table no. 2)

Out of 144 cases of Nodal-NHL, maximum 128 cases (88.89\%) expressed B-cell antigen and were classified as B-cell NHL. 12(8.33\%) cases of Nodal-NHL expressed T-cell antigen and were classified as T-cell NHL. 4(2.78\%) cases could not be phenotyped due to lack of expression of B or T cell antigen, were clubbed as high grade blastoid lymphoma. (Table no. 3) These would require molecular studies for further evaluation.

DLBCL was the commonest NHL being $61.11 \%$ in the present study. The second commonest was SLL/CLL being $11.11 \%$ cases, followed by follicular lymphoma in $5.56 \%$ cases. Amongst the B cell NHL, the low grade 
subtypes were SLL $11.11 \%$ cases, mantle cell lymphoma $4.16 \%$ cases, marginal zone lymphoma $2.78 \%$ cases and follicular lymphoma $5.56 \%$ cases. The high grade subtypes were DLBCL $61.11 \%$ cases, Burkitt's lymphoma $1.39 \%$ cases and lymphoblastic lymphoma $1.39 \%$ cases. Amongst the T cell lymphoma, lymphoblastic lymphoma was commonest being $4.16 \%$ cases, followed by anaplastic large cell lymphoma $2.78 \%$ cases and angioimmunoblastic lymphoma $1.39 \%$ cases. (Table no. 3) Max no. of cases of
DLBCL, SLL/CLL, mantle cell lymphoma and marginal zone lymphoma were diagnosed in $>40$ years of age. Max no. of cases of Burkitt's lymphoma, lymphoblastic lymphoma of B cell, lymphoblastic lymphoma of $\mathrm{T}$ cell and anaplastic large cell lymphoma were diagnosed in $<30$ years of age. (Table no. 4) Male predominance was noted in $65.98 \%$ cases of NHL. Cervical lymph node was commonest site of involvement in our study and was noted in $62.5 \%$ cases of NHL. (Table no. 5 )

Table 1: Distribution of 147 cases with provisional diagnosis of NHL on the basis of morphology (Morphologic groups based on cell size).

\begin{tabular}{|c|c|c|c|}
\hline \multicolumn{2}{|l|}{ Morphological diagnosis } & \multirow{2}{*}{$\begin{array}{l}\mathbf{N} \\
35\end{array}$} & \multirow{2}{*}{$\begin{array}{c}\% \\
23.81 \\
\end{array}$} \\
\hline NHL with "small size cells" 35 (23.81\%) & Low Grade NHL & & \\
\hline $\begin{array}{l}\text { NHL with Medium to large "centroblastic } \\
\text { and centrocytic cells" } 80(54.42 \%)\end{array}$ & Intermediate grade NHL & 80 & 54.42 \\
\hline \multirow{2}{*}{$\begin{array}{l}\text { NHL with Medium to large "Blastoid cells" } \\
14(9.52 \%)\end{array}$} & High grade NHL (Lymphoblastic lymphoma) & 13 & 8.84 \\
\hline & High grade NHL (Burkitt's lymphoma) & 1 & 0.68 \\
\hline $\begin{array}{l}\text { NHL with large "immunoblastic cells" } 18 \\
(12.25 \%)\end{array}$ & High Grade NHL (immunoblastic) & 18 & 12.25 \\
\hline Total & & 147 & 100 \\
\hline
\end{tabular}

Table 2: Distribution of 147 provisionally diagnosed cases of NHL(Final diagnosis on basis of IHC).

\begin{tabular}{|c|c|c|c|}
\hline \multicolumn{2}{|l|}{ Final diagnosis of NHL } & \multirow{2}{*}{$\begin{array}{c}\text { No } \\
88\end{array}$} & \multirow{2}{*}{$\begin{array}{c}\% \\
61.11\end{array}$} \\
\hline Nodal NHL & Diffuse large B cell lymphoma (DLBCL) & & \\
\hline & Low Grade Non-Hodgkin's Lymphoma-SLL/CLL & 16 & 11.11 \\
\hline & Follicular Lymphoma & 8 & 5.56 \\
\hline & Mantle Cell Lymphoma & 6 & 4.16 \\
\hline & Marginal Zone lymphoma & 4 & 2.78 \\
\hline & Lymphoblastic Lymphoma of T cell phenotype & 6 & 4.16 \\
\hline & Lymphoblastic Lymphoma of B cell phenotype & 2 & 1.39 \\
\hline & High Grade blastoid Non-Hodgkin's Lymphoma & 4 & 2.78 \\
\hline & Anaplastic Large cell lymphoma & 4 & 2.78 \\
\hline & Burkitt's Lymphoma & 2 & 1.39 \\
\hline & T cell rich-Diffuse large B cell lymphoma (T-DLBCL) & 2 & 1.39 \\
\hline & Angioimmunoblastic lymphoma of $\mathrm{T}$ cell phenotype & 2 & 1.39 \\
\hline \multicolumn{2}{|l|}{ Total } & 144 & 100 \\
\hline \multicolumn{2}{|c|}{ Final diagnosis of "Other than NHL" } & \multicolumn{2}{|c|}{ No } \\
\hline \multirow[t]{2}{*}{ Carcinoma (2) } & Metastatic Anaplastic large cell Carcinoma & \multicolumn{2}{|c|}{1} \\
\hline & Metastatic Small cell Neuroendocrine Carcinoma & \multicolumn{2}{|c|}{1} \\
\hline Hodgkin's lymphoma (1) & Hodgkin's Lymphoma & \multicolumn{2}{|c|}{1} \\
\hline \multicolumn{2}{|l|}{ Total } & \multicolumn{2}{|c|}{3} \\
\hline
\end{tabular}


Table 3: Distribution of 144 cases of nodal-NHL (WHO classification).

\begin{tabular}{|c|c|c|c|}
\hline \multicolumn{2}{|l|}{ WHO classification } & \multirow{2}{*}{$\begin{array}{l}\text { No } \\
88\end{array}$} & \multirow{2}{*}{$\begin{array}{c}\% \\
61.11\end{array}$} \\
\hline \multirow{8}{*}{$\begin{array}{l}\text { B-cell lymphoma } \\
128(88.89 \%)\end{array}$} & Diffuse large B cell lymphoma (DLBCL) & & \\
\hline & SLL/CLL & 16 & 11.11 \\
\hline & Follicular Lymphoma & 8 & 5.56 \\
\hline & Mantle Cell Lymphoma (MCL) & 6 & 4.16 \\
\hline & Marginal Zone lymphoma (MZL) & 4 & 2.78 \\
\hline & Burkitt's Lymphoma & 2 & 1.39 \\
\hline & Lymphoblastic Lymphoma of B cell phenotype & 2 & 1.39 \\
\hline & T cell rich-Diffuse large B cell lymphoma (T-DLBCL) & 2 & 1.39 \\
\hline \multirow{3}{*}{ T-cell Lymphoma 12 (8.33\%) } & Lymphoblastic Lymphoma of T cell phenotype & 6 & 4.16 \\
\hline & Anaplastic Large cell lymphoma & 4 & 2.78 \\
\hline & Angioimmunoblastic lymphoma of T cell phenotype & 2 & 1.39 \\
\hline Unclassified $4(2.78 \%)$ & High Grade blastoid NHL & 4 & 2.78 \\
\hline Total & & 144 & 100 \\
\hline
\end{tabular}

Table 4; Distribution of 144 cases of Nodal-NHL according to age (Age distribution).

\begin{tabular}{|l|c|c|}
\hline Age group & No & \% \\
\hline$<10$ & 6 & 3.17 \\
\hline 10 to 20 & 5 & 8.33 \\
\hline 21 to 30 & 12 & 13.89 \\
\hline 31 to 40 & 20 & 29.86 \\
\hline 41 to 50 & 43 & 19.44 \\
\hline 51 to 60 & 28 & 20.84 \\
\hline$>60$ & 30 & 100 \\
\hline Total & 144 & 2 \\
\hline
\end{tabular}

Table 5: Distribution of 144 cases of Nodal-NHL according to Site (Lymph node group involvement).

\begin{tabular}{|l|c|c|}
\hline & No & 62.5 \\
\hline Cervical L.N & 90 & 49.31 \\
\hline Cervical L.N & 71 & 8.33 \\
\hline (b) Submandibular L.N & 12 & 1.39 \\
\hline (c) Submental L.N & 2 & 3.47 \\
\hline (d) Supraclavicular L.N & 5 & $\mathbf{6 . 9 4}$ \\
\hline Intra-abdominal L.N & 10 & 2.78 \\
\hline Mesentric L.N & 4 & 2.08 \\
\hline Retroperitoneal L.N & 3 & 2.08 \\
\hline (c) Abdominal L.N & 3 & 15.97 \\
\hline Inguinal L.N & $\mathbf{2 3}$ & $\mathbf{1 . 3 9}$ \\
\hline Mediastinal L.N & $\mathbf{2}$ & $\mathbf{1 3 . 2 0}$ \\
\hline Axillary L.N & 19 & 100 \\
\hline Total & 144 & \\
\hline
\end{tabular}


Table 6: Importance of immunohistochemistry.

\begin{tabular}{|c|c|c|c|}
\hline Diagnosis & Positive markers & Negative markers & Importance of immunohistochemistry \\
\hline DLBCL & CD20 & CD3 & Essential \\
\hline BL & CD20, MIB1 $(100 \%)$ & - & Necessary \\
\hline SLL/CLL & CD20 \& CD23 & Cyclin D1, Bcl-2 & Necessary \\
\hline MCL & CD20 \& Cyclin D1 & Cyclin D1 \& Bcl-6 & Negative markers are essential \\
\hline MZL & CD20 & Cyclin D1, Bcl-2 \&CD23 & Essential \\
\hline FL & CD20 \&Bcl-2 & CD23 \& Cyclin D1 & Essential \\
\hline LL of B cells & CD99, Tdt \& Pax-5 & - & Essential \\
\hline LL of T cells & CD3, CD99 \& Tdt & - & - \\
\hline ALCL & CD3, CD30 \& Alk protein &
\end{tabular}

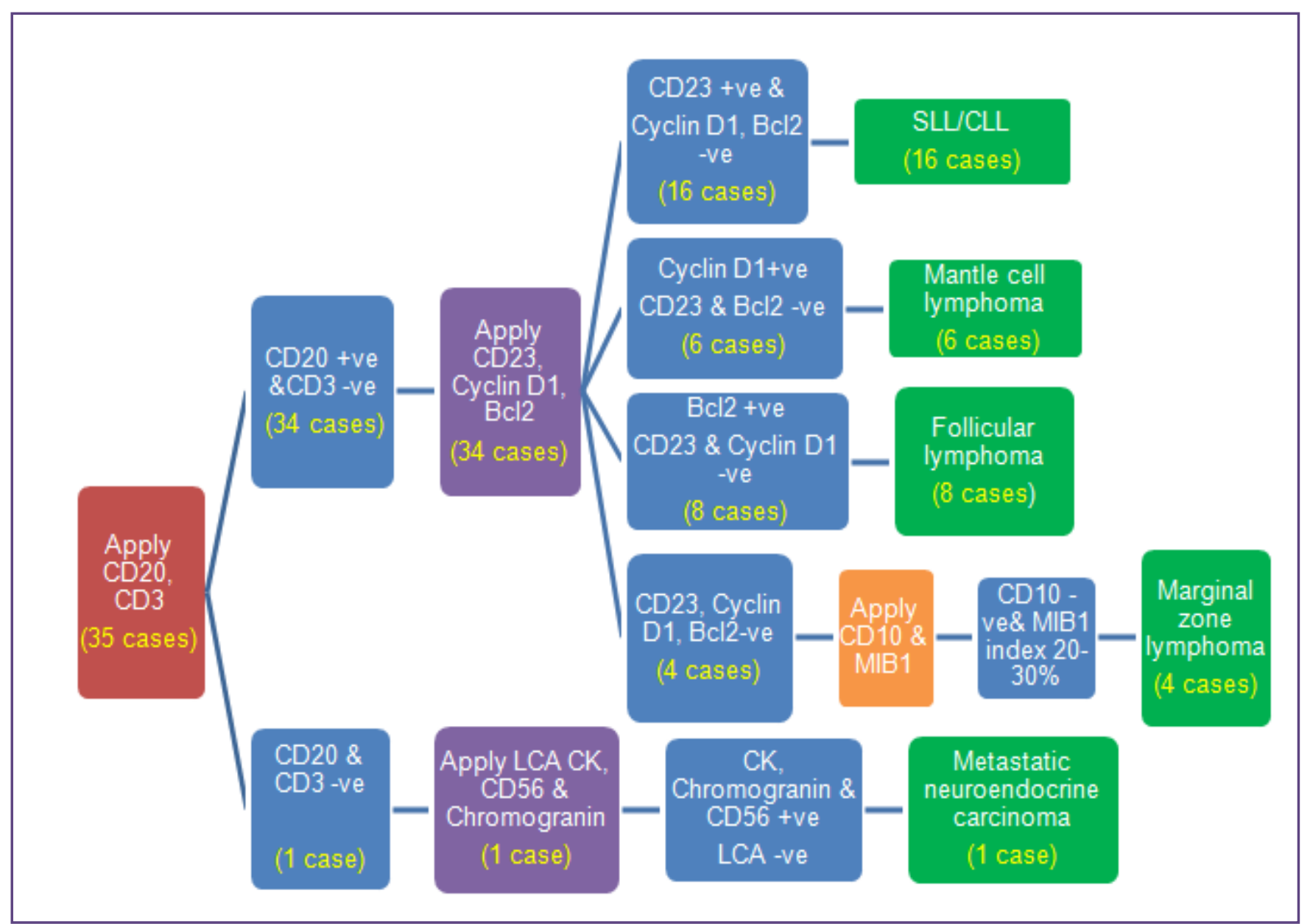

Flowchart: 1. Antibody panels used for diagnosis of NHL with "small \& mature lymphoid cells" 


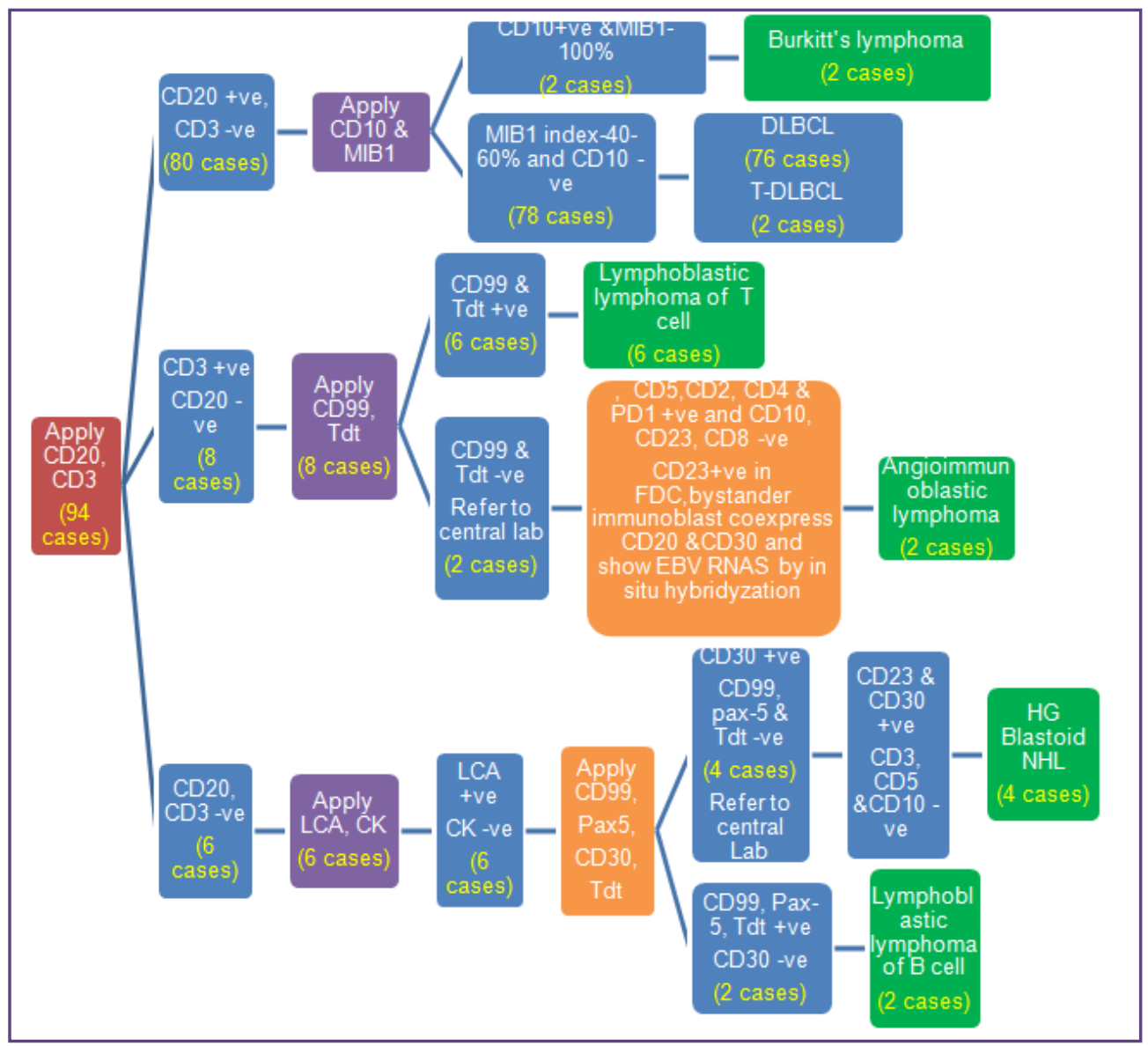

Flowchart: 2. Antibody panels used for diagnosis of NHL withmedium to large "Blastoid cells" and NHL with medium to large "centroblastic \& centrocytic cells".



Flowchart: 3. Antibody panels used for diagnosis of NHL with “large (Immunoblastic) cells". 


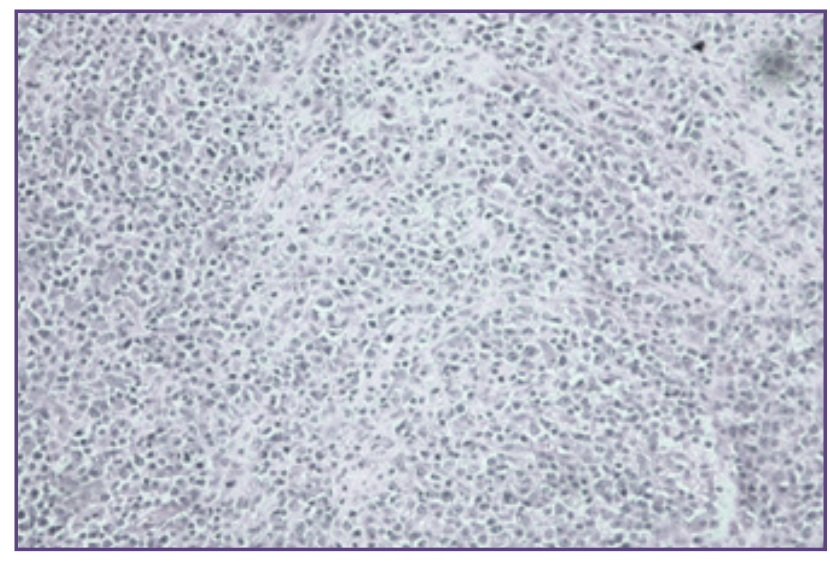

DLBCL-The tumor cells have large nuclei with dispersed chromatin, small nucleoli, and a variable amount of cytoplasm. (H \& E section 100X).

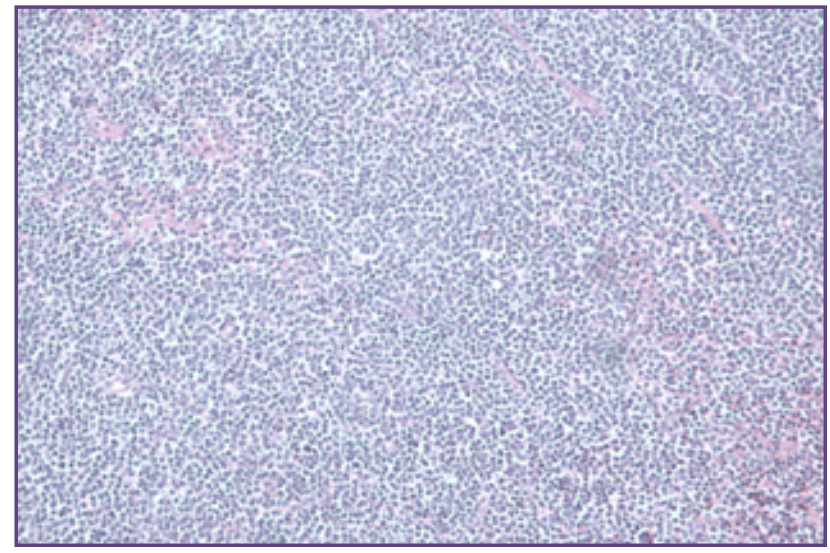

SLL/CLL- diffuse alteration of architecture, proliferation center that is composed of intermediate-sized cells with small nucleoli that are surrounded by small round lymphocytes. (H \& E section 100X)

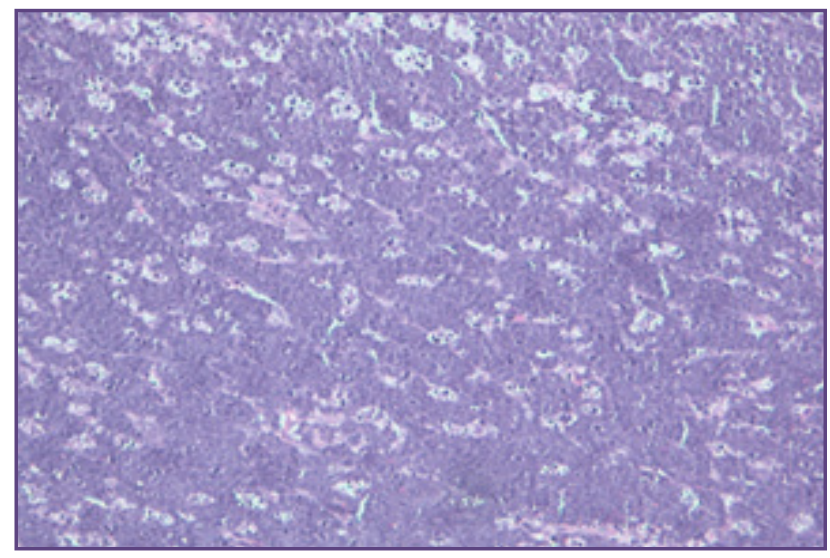

Burkitt lymphoma- Sheets of medium-sized lymphocytes are present with fine chromatin and multiple nucleoli. In addition, there are scattered large histiocytes containing debris. These histiocytes give the "starry sky" appearance to the histology of Burkitt lymphoma. (H \& E section 100X)

\section{Discussion}

During the study period a total of 147 cases with provisional morphological diagnosis of Nodal NHL were selected. There were grouped according to cell size and grade into three groups (viz. NHL with small \& mature cells, NHL with medium to large cells and NHL with large immunoblastic cells). Panel of antibodies was decided according to the morphological group and were applied in a step wise manner.

Out of total 147 provisionally diagnosed (on basis of morphology) cases of NHL, 144 cases $(97.96 \%)$ were diagnosed as NHL and 3 cases $(2.04 \%)$ were diagnosed as other than NHL (carcinoma and Hodgkin's lymphoma) on IHC. (Table no. 2) Our study reports $97.96 \%$ overall concordance between light microscopy and IHC studies in the diagnosis of NHL. H Hjalgriml et al. ${ }^{11}$ reported similar percentage of concordance in the study period of 1978-89 being 98\%. Lower concordance is seen in the study of Anjali S. Kulkarni et al. ${ }^{12}$ who reported $81.4 \%$ concordance between light microscopy and IHC studies. Lower percentage of concordance could also be, because of larger percentage of reactive lymphadenopathy (HIV associated) and Hodgkin's lymphomas in their study which are challenging to diagnose on morphology alone.

NHL could be classified using working formulation into low grade $(23.81 \%)$, Intermediate grade $(54.42 \%)$ and High grade $(21.77 \%)$ on basis of morphology, and each group was further sub typed on basis of cell size and maturity. (Table no. 1) Aggarwal D et al. ${ }^{13}$ and Sudipta Chakrabarti et al. ${ }^{14}$ and Elizabeth A. Holly et al. ${ }^{15}$ reported Intermediate grade NHL to be the commonest lymphoma being $65.38 \%$, $55.3 \%$ and $53 \%$ respectively.

B-cell lymphoma predominated being $88.89 \%$ cases, followed by T-cell lymphoma being $8.33 \%$ cases. (Table no. 3) This B cell lymphoma preponderance has been

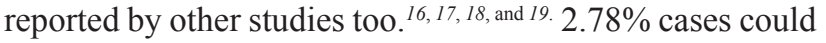
not be phenotyped due to lack of expression of B or T cell antigen, were clubbed as high grade blastoid lymphoma. (Table no. 3) These would require molecular studies for further evaluation. Our study was concordance with the studies by Naresh K.N et al. ${ }^{16}$, Kalyan K et al. ${ }^{17}$ and Roy A et al. ${ }^{20}$ who reported unclassified NHL being 5.6\%, 5.6\% and $7.4 \%$ respectively.

\section{Inability to classify NHL into B \& $T$ cell phenotype in} their studies, could be due to

1. Poor antigen preservation despite a morphology characteristic of lymphoma.

2. Non-conformance to the defined entities despite good morphology and complete immunohistochemical workup. 
Amongst the B cell NHL, DLBCL was the commonest being $61.11 \%$ in the present study. The second commonest was SLL/CLL being $11.11 \%$ cases, followed by follicular lymphoma in $5.56 \%$ cases. (Table no. 3) Majority of studies by Mushtaq $\mathrm{S}$ et al. ${ }^{18}$, Manisha Sharma et al. ${ }^{19}$, Qun-pei Yang et al. ${ }^{21}$, Vallabhajosyula $\mathrm{S}$ et al. ${ }^{22}$, Naresh K.N et al. ${ }^{16}$, Roy A et al. ${ }^{20}$, Kalyan K et al. ${ }^{17}$ and Anjali S. Kulkarni et al. ${ }^{12}$ reported diffuse large cell lymphoma to be the commonest NHL with great variation in percentage, being $76 \%, 46.8 \%, 39.8 \%, 37.6 \%, 34 \%, 29.3 \%, 26 \%$ and $23 \%$ respectively.

Amongst the $\mathrm{T}$ cell lymphoma, lymphoblastic lymphoma was commonest being $4.16 \%$ cases, followed by anaplastic large cell lymphoma $2.78 \%$ cases and angioimmunoblastic lymphoma $1.39 \%$ cases. (Table no. 3) Our study concordance with the study by Naresh K.N et al. ${ }^{16}$ and Mushtaq et al. ${ }^{18}$ who reported lymphoblastic lymphoma in $6.6 \%$ and $6.11 \%$ cases respectively. Naresh K.N et al. ${ }^{16}$ reported similar percentage of anaplastic large cell lymphoma and angioimmunoblastic T-cell lymphoma in their study being $4.1 \%$ and $1.0 \%$ respectively.

In the present study, WHO classification has proved to be superior when compared to working formulation has been able to phenotype and subdivide prognostically different types of NHL. However, importance of morphology lies in the ability for grouping the NHL according to "cell size" so that panel of antibodies can be chosen to apply in a step wise manner. This optimizes the no. of antibodies and is cost effective.

\section{Limitations of working formulation:}

- Working formulation is entirely based on morphology and hence is subjective and depends on the expertise and experience of reporting pathologist.

- $\quad$ Being based on morphology alone it fails to subtype NHL into B or T cell lymphoma.

- The grading and subtyping is subjective and is known to have low reproducibility.

- There are chances of misdiagnosis of lymphoblastic lymphoma and Burkitt's lymphoma as in some cases the morphology resembles DLBCL.

- The mimicker of NHL cannot be diagnosed with authenticity without markers e.g. carcinoma, Hodgkin's lymphoma, reactive hyperplasia.

Mushtaq S et al. ${ }^{18}$ reported that by using WHO classification with the help of immunohistochemical techniques, various subtypes of NHL are easily classified into B and T cell types and to identify newer entities for more precise diagnosis and proper management of patients. Kalyan $\mathrm{K}$ et al. ${ }^{17}$ reported that WHO classification of NHL is based on morphology and immunohistochemical expression of the lymphoma cells and to a lesser extent, on the molecular and cytogenetic findings, which helps subdivide prognostically different types of NHL.

A few cases $(4.16 \%)$ could not reach a final diagnosis with the basic panel of antibodies in our laboratory and were referred to a tertiary central laboratory for a higher panel of antibodies and molecular studies \& interpretation by experts.(Table no. 3)

The antibodies used for IHC study were CD20, CD3, CD23, Cyclin D1, Bcl2, CD10, MIB1, CD99, Tdt, LCA, Pax5, CD30, CD15, CD3, CD5, CD2, CD4, PD1, CD8, Alk protein, CK, Chromogranin, CD56 and S100 in our study.

Maximum no. of cases of NHL could be diagnosed with 3-8 antibodies. Only 4.16\% cases of NHL required a large panel of antibodies being 3-12. Naresh KN et al. ${ }^{16}$ and Manisha Sharma et al. ${ }^{19}$ reported that panel of antibodies used in their studies varied from 3-12 and 5-11 respectively.

Small cell neuroendocrine carcinoma: One case with small cells was negative for CD20, CD3 \& LCA antibodies and diagnosed as "Other than NHL". (Table no. 2) The cells showed positivity for $\mathrm{CK}$, Chromogranin and CD56 antibodies (in second panel), was labelled as neuroendocrine carcinoma. R. N. Waduge et al. ${ }^{23}$ reported that small cell lymphoma were mimicked by neuroendocrine tumor in their study which confirmed and diagnosed by CD56, CK and LCA antibodies.

Carcinoma \& Hodgkin's Lymphoma: 2 cases were diagnosed as "Other than NHL". Out of these 2 cases, 1 case diagnosed as Hodgkin's lymphoma showed positivity for CD30 \&CD15 antibodies and negativity for LCA antibody and 1 case diagnosed as metastatic anaplastic carcinoma showed positivity for CK antibody and negativity for S100, LCA CD20 \& CD3 antibodies. (Table no. 2)

Max no. of cases $(70.14 \%)$ of NHL were diagnosed in $>40$ years of age. (Table no. 4) Results of study conducted by Roy A et al. ${ }^{20}$, was in agreement with our study. It reported that $63.6 \%$ NHL occurred after the age of 40 years with a peak between 51 and 60. Similarly, in a study conducted by Vallabhajosyula et al. ${ }^{22}$, interquartile range was 41-67 years. Max no. of cases of Burkitt's lymphoma, lymphoblastic lymphoma of B cell, lymphoblastic lymphoma of $\mathrm{T}$ cell and anaplastic large cell lymphoma were diagnosed in $<30$ years of age. Roy A et al. ${ }^{20}$ reported that Maximum cases of burkitt's lymphoma, lymphoblastic lymphoma of B cell, lymphoblastic lymphoma of $\mathrm{T}$ cell and anaplastic lymphoma were diagnosed in $<30$ years of age being $66.67 \%, 37.5 \%, 70.83 \%$ and $52.94 \%$ respectively. 
NHL is more common in older adults than younger adults; hence age presents to be strong risk factor for this disease. Incidence data obtained from the United States National Cancer Institute's Surveillance, Epidemiology, and End Results (SEER) Program accounted that the incidence of total lymphoid neoplasm increased monotonically with age in all race and sex subgroups. Steep increases in incidence with age were observed for most subtypes. ${ }^{24}$

Male predominance was noted in $65.98 \%$ cases of NHL. This male preponderance has been reported by other studies too. ${ }^{18,19,20 \text { and } 22}$

Cervical lymph node was commonest site of involvement in our study and was noted in $62.5 \%$ cases of NHL.(Table no. 5) Anjali S. Kulkarni et al. ${ }^{12}$ and Mushtaq $\mathrm{S}$ et al. ${ }^{18}$ reported that cervical lymph nodes was the commonest group affected in NHL.

\section{Conclusion}

WHO classification for NHL enables to diagnose and subtype the NHL into clinically and prognostically relevant entities. Morphological grouping of NHL by cell size \& grade and followed by application of antibody panel in a stepwise manner would optimise the number of antibodies used and be more cost effective.

In the present clinical scenario of targeted specific chemotherapy regimens available for specific NHL, every case of NHL should be evaluated by IHC markers, for accurate subtyping and to rule out mimickers of NHL like Hodgkin's lymphoma and carcinoma. An IHC lab with a panel of CD20, CD3, CD23, Cyclin D1, Bc16, CD10, MIB1, LCA, CD99, Tdt, Pax-5, CD5, CD2, CD4, PD1, CD30, Alk protien, CD15, CK, Chromogranin, CD56, \& S100 antibodies could be able to accurately diagnose and subtype $95.83 \%$ cases of NHL. A few cases (4.17\%) could not reach a final diagnosis with the basic panel of antibodies in our laboratory. A small percentage $(2.78 \%)$ of NHL that remain unclassified by morphology and IHC study, will require higher technologies like flowcytometry, molecular and genetic studies for reaching conclusive diagnosis.

\section{Referance}

3. Jose BO, Koerner P, Spanos WJ Jr, Paris KJ, Silverman CL, Yashar C, et al. Hodgkin's lymphoma in adults - clinical features. J Ky Med Assoc 2005; 103:15-17.

4. Seow A, Lee J, Sng I, Fong CM, Lee HP. Non-Hodgkin's lymphoma in an Asian population: 1968-1992 time trends and ethnic differences in Singapore. Cancer, 1996 May; 77(9): 1899-1904.

5. Gurney KA, Cartwright RA. Increasing incidence and descriptive epidemiology of extranodal non-Hodgkin lymphoma in part of England and Wales. Hematol J, 2002; 3: 95-104.

6. Hicks EB, Rappaport H, Winter WJ. Follicular lymphoma: a re-evaluation of its position in the scheme of malignant lymphoma, based on a survey of 253 cases. Cancer 1956; 9(4):792-821.

7. Lennert K, Stein H, Kaiserling E. Cytological and functional criteria for the classification of malignant lymphomata. Br J Cancer 1975; 31(S2):29-43.

8. Lukes RJ, Collins RD. Immunologic characterization of human malignant lymphomas. Cancer 1974; 34(S8):14881503 .

9. Garvin AJ, Simon R, Young RC, DeVita VT, Berard CW. The Rappaport Classification of Non Hodgkin's Lymphoma: a closer look using other proposed classifications. Semin Oncol. 1980 Sep; 7(3):234-243.

10. Rosenberg S, Berard C, Brown Jr. B, Burke J, Dorfman R, Glatstein E, et al. National Cancer Institute sponsored study of classifications of non-Hodgkin's lymphomas: summary and description of a working formulation for clinical usage. The Non Hodgkin's Lymphoma Pathologic Classification Project. Cancer 1982; 49(10):2112-2135.

11. A clinical evaluation of the International Lymphoma Study Group classification of non-Hodgkin's lymphoma. The NonHodgkin's Lymphoma Classification Project. Blood 1997; 89(11):3909-3918.

12. John P. Greer, Michael E. Williams. Non-Hodgkin Lymphoma in Adults. In: John P. Greer, John Foerster, George M. Rodgers, Frixos Paraskevas, Bertil Glader, Daniel A. Arber, Robert T. Means Jr. (eds.) Wintrobe's clinical Hematology. 12th edition. Philadelphia, Lippincott Williams \& Wilkins; 2009. 2145-2194. (11)

13. H Hjalgrim, M Frisch, K Begtrupand, M Melbye. Recent increase in the incidence of non-Hodgkin's lymphoma among young men and women in Denmark. British Journal of Cancer 1996; 73: 951-954.(42)

14. Anjali S. kulkarni, Anjali P. Ingle, Pragati P. Phulgirkar, Manjusha S. Dhawale, Neela R. Kumbhakarna, Rajan S. Bindu. Morphological Typing of Nodal and ExtraNodal Non-Hodgkin's Lymphoma. Indian Medical Gazette.2011:438-441. (53)

15. Aggarwal D, Gupta R, Singh S, Kudesia M. Comparision of working formulation and REAL classification of nonHodgkin's lymphoma: an analysis of 52 cases. Hematology, 2011 Jul; 16(4): 195-199 (64)

16. Sudipta Chakrabarti, Supriya Sarkar, Bidyut Krishna Goswami, Srikrishna Mondal, Amitabha Roy, Shikha Das. Hodgkin's and Non-Hodgkin's Lymphomas in an Indian Rural Medical Institution: Comparative Clinicopathologic Analysis. Asian Pacific Journal of Cancer Prevention, Vol 11, 2010; 1605-1608. (65)

17. Elizabeth A Holly and Paige M Bracci. Populationbased Study of Non-Hodgkin Lymphoma, Histology, and 
Medical History among Human Immunodeficiency Virusnegative Participants in San Francisco. American Journal of Epidemiology 2003; 158: 316- 327. (66)

18. Naresh KN, Srinivas V, Soman CS. Distribution of various subtypes of non- Hodgkin's lymphoma in India: a study of 2773 lymphomas using R.E.A.L. and WHO Classifications. Ann Oncol. 2000; 11 Suppl 1:63-67. (45)

19. Kalyan K, Basu D, Soundararaghavan J. Immunohistochemical typing of non- Hodgkin's lymphomacomparing working formulation and WHO classification. Indian J Pathol Microbiol. 2006 Apr;49(2):203-207. (49)

20. Mushtaq S, Akhtar N, Jamal S, Mamoon N, Khadim T, Sarfaraz T et al., Malignant lymphomas in Pakistan according to the WHO classification of lymphoid neoplasm. Asian Pac J Cancer Prev. 2008 Apr-Jun; 9 (2):229-232. (50)

21. Manisha Sharma, Rahul Mannan, Mohit Madhukar, Sanjay Navani, Mridu Manjari, Tejinder Singh Bhasin et al. Immunohistochemical analysis of Non hodgkin's lymphoma spectrum according to WHO/REAL classification: Single centre experience from Punjab, India. Journal of Clinical and Diagnostic Research. 2014 Jan, Vol-8(1): 46-49. (55)
22. Roy A, Kar R, Basu D, Badhe BA. Spectrum of histopathologic diagnosis of lymph node biopsies: A descriptive study from a tertiary care center in South India over 51/2 years. Indian J Pathol Microbiol. 2013; 56: 103108. (54)

23. Qun-Pei Yang, Wen-Yan Zhang, Jian-Bo Yu, Sha Zhao, Huan $\mathrm{Xu}$, Wei-Ya Wang, et al. Subtype distribution of lymphomas in Southwest China: Analysis of 6,382 cases using WHO classification in a single institution. Diagnostic Pathology 2011, 6:77 (60)

24. Vallabhajosyula S, Baijal G, Vadhiraja B M, Fernandes DJ, Vidyasagar M S. Non- Hodgkin's lymphoma: Is India ready to incorporate recent advances in day to day practice?. J Can Res Ther. 2010; 6: 36-40. (61)

25. R.N Waduge, N.V.I. Ratnatunga, S. Ramadasa. Unusual histological features of Non-Hodgkin's lymphoma: a clinicopathological and immunohistochemical study. Journal of diagnostic pathology. 2002-2003; 1: 17-21. (73)

26. Morton LM, Wang SS, Devesa SS, Hartge P, Weisenburger DD, Linet MS. Lymphoma incidence patterns by WHO subtype in the United States, 1992- 2001. Blood. 2006 Jan 1; 107(1):265-276. (48)

*Corresponding author:

Dr Jaimini Patel, H-26 Sardardham, Dediyasan GIDC, Modhera Road, Gujarat 384002

Phone: +91 9909904219

Email: Jaimini1988bd@gamil.com

Financial or other Competing Interests: None. 